\title{
ASO Author Reflections: What is the Best Therapeutic Strategy for Patients with Limited Synchronous Peritoneal Metastases of Colorectal Cancer?
}

\author{
Antoine Mariani, $\mathrm{MD}^{1}$, and Diane Goere, $\mathrm{MD}, \mathbf{P h D}^{1,2}$ \\ ${ }^{1}$ Department of Visceral and Oncological Surgery, Gustave Roussy, Villejuif Cedex, France; ${ }^{2}$ Department of Visceral and \\ Oncologic Surgery, Hôpital Saint-Louis, APHP, Paris, France
}

\section{PAST}

Peroperative diagnosis of limited peritoneal metastases during surgery of colorectal cancer is a situation that can occur in a colorectal surgeon's life. However, no evidence exists to indicate the best therapeutic strategy to offer. This study compared the two principal strategies: resection of the primary tumor and peritoneal metastases with concomitant versus subsequent hyperthermic intraperitoneal chemotherapy. ${ }^{1}$

\section{PRESENT}

For incidental limited colorectal peritoneal metastases (CRPM) diagnosed during primary tumor resection, even if no significant difference in terms of survival is shown, it is the authors' view that one-stage curative treatment is preferable, avoiding a supplementary surgical procedure. Given the critical issues associated with completeness of resection, patients should be referred to centers specialized in peritoneal surgery.

ASO Author Reflections offer a brief invited commentary on the article, Strategies for Managing Intraoperative Discovery of Limited Colorectal Peritoneal Metastases. Ann Surg Oncol. 2019;26:1437-44.

(C) Society of Surgical Oncology 2019

First Received: 17 July 2019;

Published Online: 30 October 2019

D. Goere, $\mathrm{MD}, \mathrm{PhD}$

e-mail: diane.goere@aphp.fr

\section{FUTURE}

Due to negative results from the two last important trials of peritoneal colorectal cancers (PRODIGE7 and PROPHYLOCHIP), ${ }^{2,3}$ some surgeons consider that referring patients is not necessary. But cytoreductive surgery is specific and needs peritoneal expertise. Otherwise, the oncologic results are likely to be worse in the next few years. We must be cautious and continue to urge general surgeons to refer these patients. New clinical trials are necessary to answer this question definitively.

DISCLOSURE There are no conflict of interest.

\section{REFERENCES}

1. Mariani A, Gelli M, Sourrouille I, et al. Strategies for managing intraoperative discovery of limited colorectal peritoneal metastases. Ann Surg Oncol. 2019;26:1437-44.

2. Quenet F, Elias D, Roca L, et al. A UNICANCER phase III trial of hyperthermic intra-peritoneal chemotherapy (HIPEC) for colorectal peritoneal carcinomatosis (PC): PRODIGE 7. J Clin Oncol. 2018;36(Suppl 18):LBA3503. https://doi.org/10.1200/JCO.2018.3 6.18 suppl.LBA3503.

3. Goere D, Glehen O, Quenet F, et al. Results of a randomized phase 3 study evaluating the potential benefit of a second-look surgery plus HIPEC in patients at high risk of developing colorectal peritoneal metastases (PROPHYLOCHIP-NTC01226394). J Clin Oncol. 2018;36(Suppl 15):3531. https://doi.org/10.1200/JCO.201 8.36.15_suppl.3531.

Publisher's Note Springer Nature remains neutral with regard to jurisdictional claims in published maps and institutional affiliations. 